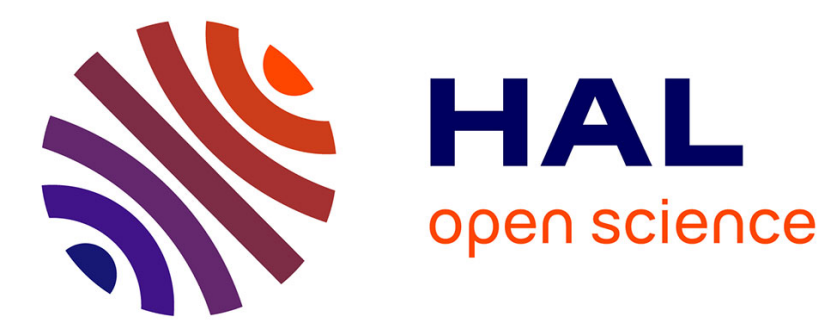

\title{
Superplastic Property of the Ti-6Al-4V Alloy with Ultrafine-Grained Heterogeneous Microstructure
}

\author{
Hiroaki Matsumoto, Takuro Nishihara, Vincent Velay, Vanessa Vidal
}

\section{To cite this version:}

Hiroaki Matsumoto, Takuro Nishihara, Vincent Velay, Vanessa Vidal. Superplastic Property of the Ti6Al-4V Alloy with Ultrafine-Grained Heterogeneous Microstructure. Advanced Engineering Materials, 2018, 20 (1), pp.1700317. 10.1002/adem.201700317 . hal-01693763

\section{HAL Id: hal-01693763 https://imt-mines-albi.hal.science/hal-01693763}

Submitted on 31 May 2018

HAL is a multi-disciplinary open access archive for the deposit and dissemination of scientific research documents, whether they are published or not. The documents may come from teaching and research institutions in France or abroad, or from public or private research centers.
L'archive ouverte pluridisciplinaire HAL, est destinée au dépôt et à la diffusion de documents scientifiques de niveau recherche, publiés ou non, émanant des établissements d'enseignement et de recherche français ou étrangers, des laboratoires publics ou privés. 


\title{
Superplastic Property of the Ti-6Al-4V Alloy with Ultrafine-Grained Heterogeneous Microstructure
}

\author{
Hiroaki Matsumoto,* Takuro Nishihara, Vincent Velay, and Vanessa Vidal
}

\begin{abstract}
Ti-6Al-4V alloy having a heterogeneous microstructure composed of ultrafine-equiaxed- $\alpha$-grains and fine-lamellar- $\alpha$-grains is investigated for microstructural changes during superplastic deformation at temperature of $700^{\circ} \mathrm{C}$. The Ti-6Al-4V alloy having an optimum fraction of fine-lamellar- $\alpha$-grains exhibits an excellent superplastic property and the highest elongation of $583 \%$ (tested at $700^{\circ} \mathrm{C} 10^{-3} \mathrm{~s}^{-1}$ ). This is mainly due to the optimized activation of grain-boundary-sliding and additional accommodation mechanism associated with frequent occurrences of dynamic recrystallization and $\beta$ precipitation at boundaries during deformation of the heterogeneous starting microstructure. The present result suggests the possibility that optimizing the starting microstructure so as to have an optimum heterogeneousmicrostructure serves as an additional stress accommodation mechanism and leads to a large superplastic elongation.
\end{abstract}

\section{Introduction}

Ti-6Al-4V alloy (hereafter designated as Ti-64 alloy) is widely used in aerospace applications because of its high specific strength and high formability associated with superplasticity. ${ }^{[1]}$ For enhancement of superplastic property, the microstructure with a grain size less than $10 \mu \mathrm{m}$, an equiaxed grain shape, and a relatively homogeneous structure is more preferable. ${ }^{[2]}$ In fact, refining the microstructure of Ti-64 alloy has resulted in excellent superplastic property associated with frequent occurrence of grain boundary sliding (GBS) $\cdot{ }^{[3-8]}$ Quite recently, Alabort et al. ${ }^{[9]}$ and Zherebtsov et al. ${ }^{[10]}$ have reported superplastic behavior of Ti-64 alloy in detail. In order to enhance superplastic properties, it requires frequent activation of accommodation mechanism of stress concentration. Accommodation mechanisms during superplastic deformation are generally distinguished as grain boundary migration, grain rotation recrystallization, diffusional mass transport, and slip in grain. ${ }^{[11,12]}$ In addition, stress induced phase transformation such as preferred

Dr. H. Matsumoto, T. Nishihara

Department of Advanced Materials Science,

Faculty of Engineering, Kagawa University, $2217-$

20 Hayashi-cho, Takamatsu, Kagawa 761-0396,

Japan

E-mail: matsu_h@eng.kagawa-u.ac.jp

Dr. Vincent Velay, Dr. Vanessa Vidal

Université de Toulouse, CNRS Mines Albi, INSA,

ISAE, ICA (Institut Clément Ader) - Campus

Jarlard - 81013 ALBI Cedex 09, France $\beta$ precipitation has been reported to act as an additional stress accommodation mechanism at grain boundary. ${ }^{[13,14]}$ Furthermore, quite recently, the present authors have mentioned that frequent occurrence of dynamic recrystallization (under discontinuous manner) during tensile deformation (at temperatures ranging from 700 to $900^{\circ} \mathrm{C}$ ) of the Ti-64 alloy with an $\alpha^{\prime}$ martensite starting microstructure strongly acted as an accommodation mechanism, thereby resulting in an excellent tensile ductility. ${ }^{[15]}$ Motyka has also pointed out that globularization from the elongated- $\alpha$-grained starting microstructure contributed to high temperature ductility of Ti alloy. ${ }^{[16]}$ Thus, the improvement of superplastic properties depends on how often the GBS occurs and the accommodation mechanism is optimally activated.

This work aims at an enhancement of superplastic property of the Ti-64 alloy by microstructural control in order to achieve frequent occurrence of GBS and optimum activation of the accommodation mechanism. Herein, we focus on the metastable starting microstructure with quite low amount of $\beta$ phase (for an enhancement of dynamic $\beta$ precipitation during deformation as an accommodation mechanism) and formation of heterogeneous microstructure composed of an equiaxedultrafine- $\alpha$-grained (for frequent activation of GBS during deformation) and fine lamellar $\alpha$ grains (for an occurrence of DRX contributing to an accommodation mechanism for GBS). According to these concepts, the Ti-64 alloy with the heterogeneous microstructure composed of ultrafine-equiaxed-grains and fine-lamellar-grains was produced by hotrolling of the alloy having the $\alpha^{\prime}$ martensite starting microstructure, followed by detailed evaluations of microstructures and superplastic deformation behavior.

\section{Experimental Section}

The Ti-64 alloy with a chemical composition (in wt\%) of $6.00 \mathrm{Al}$, $4.20 \mathrm{~V}, 0.10 \mathrm{O}, 0.02 \mathrm{~N}$, and balance Ti was used. The Ti-64 alloy plates with initial thicknesses $\left(t_{0}\right)$ of $1.50,1.78,2.08$, and $4.12 \mathrm{~mm}$ were prepared by solution treatment at $1100^{\circ} \mathrm{C}$ for $1.8 \mathrm{ks}$ and quenching into ice water in order to obtain almost fully the $\alpha^{\prime}$ martensite acicular microstructure. The starting quenched-microstructure exhibiting an $\alpha^{\prime}$ martensite is as shown in Figure 1a. These Ti-64 alloy plates with the $\alpha^{\prime}$ microstructure were hot rolled at $750^{\circ} \mathrm{C}$ and to obtain final 
(a)

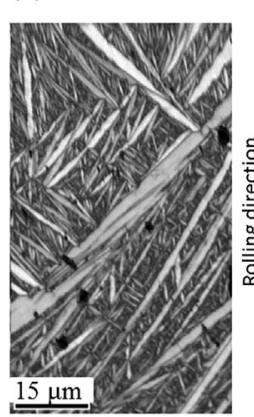

(b) $\mathrm{d}_{\text {a(equiaxed) }}=0.22 \mu \mathrm{m}$ (c) $\mathrm{d}_{\text {(s)equiaxed) }}=0.37 \mu \mathrm{m}$

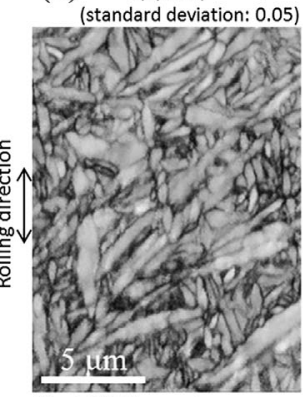

$V_{\beta}=1.6 \%( \pm 0.24 \%)$

$\rho_{G N D}=1.34 \times 10^{15}\left(\mathrm{~m}^{-2}\right)$

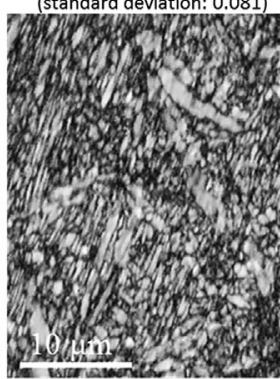

$V_{\beta}=1.8 \%( \pm 0.28 \%)$ $\rho_{G N D}=1.29 \times 10^{15}\left(\mathrm{~m}^{-2}\right)$ (d)

$\mathrm{d}_{\alpha(\text { equiaxed })}$
(standard deviation: 0.1 m

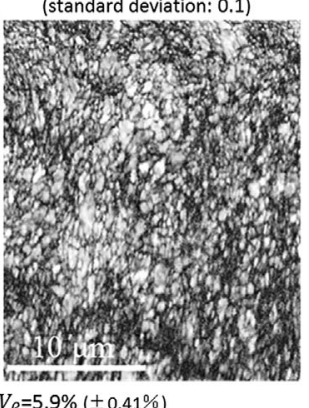

(e)

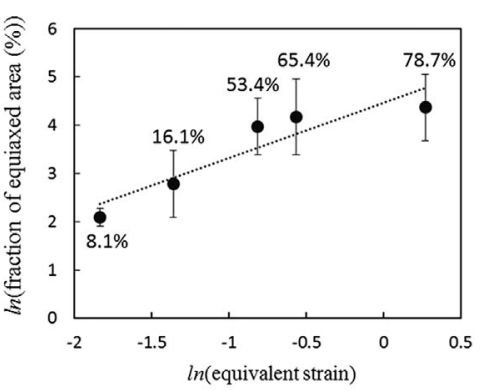

Figure 1. a-d) EBSD-band contrast images of a) the starting microstructure with an $\alpha^{\prime}$ martensite microstructure, b) the $13 \% \mathrm{HR}$ specimen, c) the $39 \%$ HR specimen, and d) the $68 \%$ HR specimen. e) Relationship between the fraction of equiaxed- $\alpha$-grains formation and the equivalent strain induced by hot rolling. Herein, the corresponding rolling reductions are also demonstrated in e).

thicknesses $\left(t_{f}\right)$ ranging from 1.31 to $2.50 \mathrm{~mm}$, resulting in rolling reductions of $13 \%\left(t_{0}=1.50 \mathrm{~mm}-t_{f}=1.31 \mathrm{~mm}\right), 20 \%$ $\left(t_{0}=1.78 \mathrm{~mm}-t_{f}=1.41 \mathrm{~mm}\right), 32 \% \quad\left(t_{0}=2.08 \mathrm{~mm}-t_{f}=1.42 \mathrm{~mm}\right)$, $39 \%\left(t_{0}=4.12 \mathrm{~mm}-t_{f}=2.5 \mathrm{~mm}\right)$, and $68 \%\left(t_{0}=4.12 \mathrm{~mm}-t_{f}=\right.$ $1.30 \mathrm{~mm})$, respectively. These hot rolled plates will be called as $13 \%, 20 \%, 32 \%, 39 \%$, and $68 \% \mathrm{HR}$, respectively. After rolling, the plates were cooled by oil-quenching.

The microstructural observations were performed at room temperature using a JEOL JSM-7001F field emission gun SEM equipped with an Oxford -HKL EBSD detector. And EBSD maps were analyzed by the HKL Channel 5 software. Samples were prepared using standard metallographic techniques and a final polish of $0.06 \mu \mathrm{m}$ colloidal silica suspension.

Tensile tests (in air atmosphere) were performed at $700^{\circ} \mathrm{C}$ and at initial strain rates ranging from $1 \times 10^{-4}$ to $1 \times 10^{-2} \mathrm{~s}^{-1}$. (Herein, testing was conducted at two times for each condition, and there is no apparent change in flow behavior. So, we judged that the testing data was reliable.) In tensile specimen, the initial gauge length was $5 \mathrm{~mm}$. Oxidation protection glass paint was coated on the surface of tensile test specimen before straining in order to reduce the influence of oxidation as much as possible. The strain rate sensitivity $m$ was evaluated using the slope of log $\sigma$ (at a true plastic strain of 0.1 )-log $\dot{\varepsilon}$ curves or strain-rate-change tests.

\section{Results and Discussion}

\subsection{Microstructures of the as-Hot-Rolled Specimens}

Figure $1 \mathrm{~b}-\mathrm{d}$ shows the EBSD-band contrast images of the as-hotrolled Ti-64 plates. Fraction of $\beta$ phase estimated by image analysis using the back-scattered SEM images and the average dislocation densities of geometrically necessary dislocations (GNDs) according to the formula $\left(\rho_{G N D}=2 \Delta \theta /(\mu b)\right)^{[17]}$ using the data of EBSD-local misorientation are also shown in Figure $1 b-d$. In the above equation, $\mu$ is the unit length corresponding to the step size in EBSD analysis $(=0.20 \mu \mathrm{m}$ in this work) and $b$ is magnitude of the Burgers vector of $\langle a\rangle$ dislocation for $\alpha$ phase $\left(=2.95 \times 10^{-10} \mathrm{~m}\right)$. Acicular martensite microstructure in starting condition is found to evolve into heterogeneous-microstructure composed of ultrafine equaxed $\alpha$-grains and fine lamellar $\alpha$-grains. In addition, we can note that the $\beta$ fraction in rolled sheet increases with an increasing rolling reduction which is attributable to static heat treatment effect. It implies that decomposition of $\beta$ from an $\alpha^{\prime}$ martensite or a supersaturated $\alpha$ phase is enhanced with an increase of rolling reduction. However, the $\beta$ fraction in rolled sheet (as shown in Figure 1) exhibits the lower fraction than the equilibrium $\beta$ fraction of $11.5 \%$ at $750^{\circ} \mathrm{C}$ in Ti-64 alloy. As stated in previous report, ${ }^{[6,14]}$ hot-rolling process of an $\alpha^{\prime}$ martensite starting microstructure resulted in formation of a metastable microstructure with quite less $\beta$ precipitates.

Evaluated fraction of equiaxed- $\alpha$-grains formation as a function of an equivalent strain under rolling is summarized in Figure 1e. The equivalent strain is expressed as following equation:

$\varepsilon=-1.15 \ln (1-r)$, in which $r$ corresponds to a rolling reduction.

With increasing an equivalent strain, the fraction of the equiaxed $\alpha$-grain region is seen to be linearly increased, indicating that refining of microstructure accompanied by an occurrence of discontinuous-DRX is proceeded with straining. According to the calculated density of GNDs (from Figure 1), there is no apparent change in the GNDs-density for all hot rolled-specimens, implying that the accumulated strains induced by hot rolling is annihilated via an occurrence of discontinuous-DRX. ${ }^{[18]}$ Hereafter, the effect of the heterogeneous microstructure (composed of the fine lamellar $\alpha$-grains and ultrafine equiaxed $\alpha$ grains) on high temperature deformation behavior would be mentioned as follows.

\subsection{Superplastic Properties}

Figure 2 summarizes tensile behaviors at $700{ }^{\circ} \mathrm{C}($ (a) true stresstrue strain curves and (b) elongation to fracture) of the $13 \%, 39 \%$, and $68 \% \mathrm{HR}$ specimens. The results of the cases in the $\alpha^{\prime}$ martensite starting microstructure (as shown by the STQ specimen $)^{[15]}$ and in the fine equiaxed starting microstructure $\left(d_{\alpha}=3 \mu \mathrm{m}\right)$ (tested at $\left.800^{\circ} \mathrm{C}\right)^{[19]}$ are also shown in Figure $2 \mathrm{~b}$. 
(a)

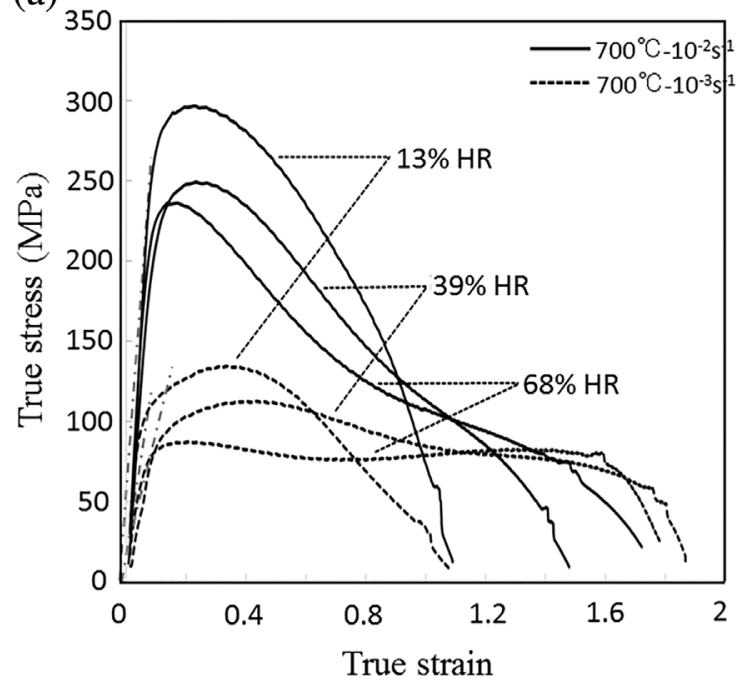

(b)

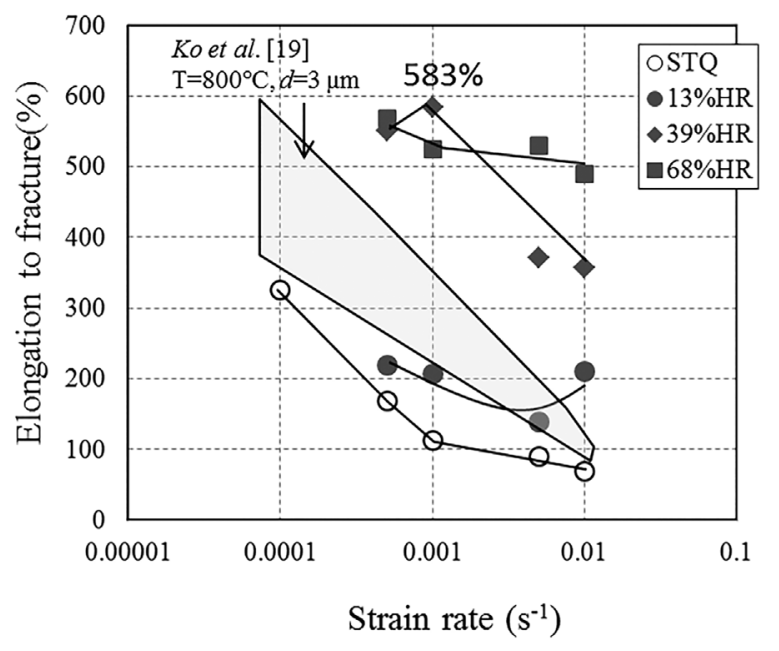

Figure 2. a) True stress-true strain curves of the $13 \% \mathrm{HR}$ specimen, $39 \% \mathrm{HR}$ specimen, and $68 \% \mathrm{HR}^{2}$ specimen tensile tested at $700^{\circ} \mathrm{C} 10^{-2} \mathrm{~s}^{-1}$ and $700^{\circ} \mathrm{C} 10^{-3} \mathrm{~s}^{-1}$. b) Summary of elongation to fracture for the hot rolled specimens (in this work) tested at $700^{\circ} \mathrm{C}$, compared with the results obtained for the STQ specimen having the $\alpha^{\prime}$ martensite starting microstructure ${ }^{[15]}$ (tested at $700^{\circ} \mathrm{C}$ ) and the Ti-64 alloy with an average grain size of $3 \mu \mathrm{m}$ (tested at $800^{\circ} \mathrm{C}$ ) (shown in hatched region). ${ }^{[19]}$

In Figure 2a, a continuous flow softening after a peak stress is clearly observed at a strain rate of $10^{-2} \mathrm{~s}^{-1}$. It can be noted, however, for the $68 \% \mathrm{HR}$ specimen, that steady state behavior appears at a later stage of deformation. At a strain rate of $10^{-3} \mathrm{~s}^{-1}$, an extensive steady state region throughout plastic deformation is observed for the $68 \% \mathrm{HR}$ specimen. In the $39 \% \mathrm{HR}$ specimen, stress-strain curve exhibits flow softening (after exhibiting a peak stress) followed by extensive steady state behavior, which is similar to the typical curve exhibiting an occurrence of discontinuousDRX. ${ }^{[20]}$ These differences in flow behavior are supposed to be derived from several factors. One is derived from the difference in fraction of equiaxed $\alpha$ grains in the starting microstructure. That is, DRX is frequently activated in fine lamellar $\alpha$-grains (corresponding to the un-DRX grains after rolling process) followed by operation of GBS for the $39 \% \mathrm{HR}$ specimen, thereby resulting in the abovementioned flow behavior. Additionally, it can be observed that the peak stress value decreases with increasing rolling reduction, implying that GBS is frequently activated from initial stage of deformation for the higher-rolling-reduction-specimen.

From Figure 2b, we can observe an increase in elongation to fracture with an increasing hot rolling reduction associated with an enhancement of equiaxed- $\alpha$-grain-formation. Herein, it can be observed that remarkable high elongations are obtained especially in the $39 \% \mathrm{HR}$ specimen and the $68 \% \mathrm{HR}$ specimen. Furthermore, it is interestingly noted that the highest elongation of $583 \%$ is exhibited in the $39 \% \mathrm{HR}$ specimen (tested at $10^{-3} \mathrm{~s}^{-1}$ ) in spite of its heterogeneous starting microstructure. In generally, it is recognized that the equiaxed grains facilitate GBS, thereby resulting in an enhancement of superplasticity. By contrast, the obtained result in this work implies that optimization of microstructural heterogeneity can lead to further enhancement of superplastic property.

A strain rate sensitivity $(m=\delta(\log \sigma) / \delta(\log \dot{\varepsilon}))$ of more than 0.3 is observed for superplastic deformation. The estimated $m$ values (at a testing temperature of $700^{\circ} \mathrm{C}$ and a true plastic strain of 0.1 ) for all hot rolled specimens are summarized in Figure 3a (showing the $m$ values as a function of fraction of equiaxed- $\alpha$-grainsformation in log-log scale), revealing that all the hot rolled specimens exhibit superplasticity. From Figure 3a, an almost linear relationship is observed, that is, the $m$ value increases with increasing fraction of the equiaxed- $\alpha$-grain. Furthermore, similar high $m$ value (more than 0.4 ) is exhibited for the $39 \% \mathrm{HR}$ specimen and the $68 \% \mathrm{HR}$ specimen. This result indeed reveals that an increasing fraction of fine equiaxed $\alpha$ grain (accompanied by an increase in rolling reduction up to $32 \%$ ) results in enhancement of superplasticity. After the rolling reductions more than $39 \%$ (for the $39 \% \mathrm{HR}$ specimen and the $68 \% \mathrm{HR}$ specimen), it is found that superplasticity is optimally activated. In order to analyze the change in strain rate sensitivity $(m)$ during deformation, the tensile strain rate jump test $\left(\right.$ at $\left.700^{\circ} \mathrm{C}\right)$ was also carried out. Herein, deformation was carried out under the condition of constant crosshead-speed (corresponding to the initial strain rate of $10^{-2} \mathrm{~s}^{-1}$ ) up to a true plastic strain of approximately 0.4 , followed by consecutive change in steps under the condition of constant true-strain-rates of $5 \times 10^{-3} \mathrm{~s}^{-1}, 10^{-3} \mathrm{~s}^{-1}, 5 \times 10^{-4} \mathrm{~s}^{-1}$, and $10^{-4} \mathrm{~s}^{-1}$. The obtained result (relationship between stress value and true strain rate in log-log scale) is given in Figure $3 \mathrm{~b}$. Figure $3 \mathrm{~b}$ also contains the graph showing the relationship between true stress and true strain. The $m$ values (at a true plastic strain above 0.4 ) reveals that the $m$ value of the $13 \% \mathrm{HR}$ specimen also exhibits more than 0.3 and the quite higher $m$ value of 0.66 is obtained in the 39\%HR specimen. Compared to the $m$ values at a true strain of 0.1 (as shown in Figure 3a), it can be interestingly noted that the $39 \% \mathrm{HR}$ specimen especially exhibits the drastic increase in $m$ value with increasing strain. This result indeed points out that GBS is frequently operative with increasing strain during deformation in the $39 \% \mathrm{HR}$ specimen having the heterogeneous starting microstructure. 


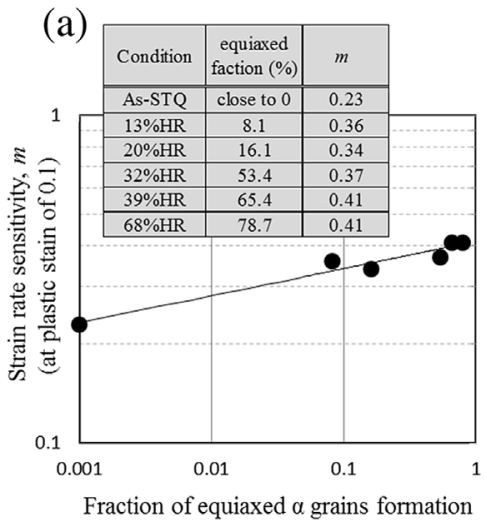

(b)

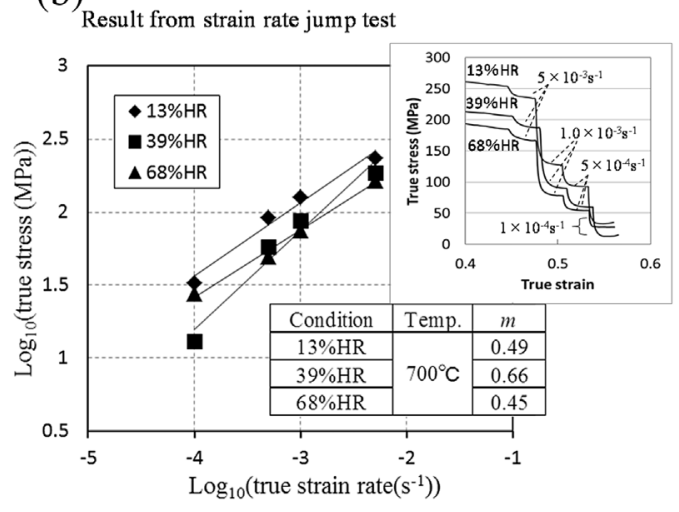

Figure 3. a) Dependence of formation of the equiaxed- $\alpha$-grains on the strain rate sensitivity ( $m$ ) (at a plastic true strain of 0.1 ) tested at $700^{\circ} \mathrm{C}$. b) Relationships of true-stress and true-strain rate (in log-log scale) and the stress-strain curves obtained by strain rate jump test (at and from a true plastic strain above 0.4 ) for the $13 \% \mathrm{HR}$ specimen, the $39 \% \mathrm{HR}$ specimen, and the $68 \% \mathrm{HR}$ specimen.

sliding under general creep conditions corresponds to $d>\lambda$ and by contrast sliding in superplasticity corresponds to $d<\lambda$. For $d<\lambda$ in superplasticity, the rate of superplastic flow is then controlled by the rate of climb of these intragranular dislocations into the opposing grain boundary. Figure $4 \mathrm{e}$ is the schematic illustration showing the expected deformation mode in the heterogeneous starting microstructure of the $39 \% \mathrm{HR}$ specimen. In the fine lamellar $\alpha$-grains, mobile dislocations accumulate in low angle boundaries resulting in a continuous increase of subgrain boundary misorientation, and so to the creation of new equiaxed grains (as a consequence of an occurrence of continuous-DRX), thereby leading to an accommodation mechanism in order to achieve continuity at the

\subsection{Superplastic Deformation Mode}

Here, the microstructural factors for enhancing superplasticity in the $39 \% \mathrm{HR}$ specimen having the heterogeneous microstructure composed of fine lamellar $\alpha$-grains and equiaxed $\alpha$ grains is discussed. As abovementioned, the area fraction of an equiaxed region in the $39 \% \mathrm{HR}$ specimen before deformation is $65.4 \%$. The deformed microstructures (given by EBSD-orientation images and inverse pole figure showing the orientation for normal direction to the rolling plane) at gage section and grip section of tensile specimen are summarized in Figure $4 \mathrm{a}-\mathrm{d}$. The grip section exhibits the microstructure associated with static isothermal annealing. From microstructures at the gage section, we can see a homogeneous equiaxed fine microstructure with higher fraction of $\beta$ precipitates and observe that no cavities are formed even after deformation at a strain rate of $10^{-2} \mathrm{~s}^{-1}$. The crystallographic orientations along the gage section are shown to be completely random, whereas that along the grip section, corresponding to the non-deformed region, are noted to be relatively accumulated in region that [0001] aligns ranging from 5 to $60^{\circ}$ parallel to normal direction to the rolling plane. These results clearly indicate the occurrence of GBS as the dominant deformation mode even at higher strain rates of $10^{-3} \mathrm{~s}^{-1}$ and $10^{-2} \mathrm{~s}^{-1}$. Under deformation of the $39 \%$ HR specimen, it can be supposed that GBS frequently operates at and from initial stage of deformation in the ultrafine equiaxed region in starting microstructure, whereas, in the fine lamellar $\alpha$-grains, DRX is activated at initial stage of deformation followed by an activation of GBS at later stage of deformation.

The grain sizes after deformation are estimated to be $0.87 \mu \mathrm{m}$

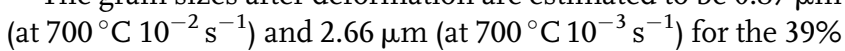

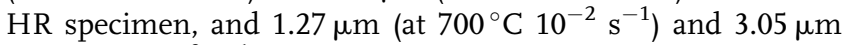

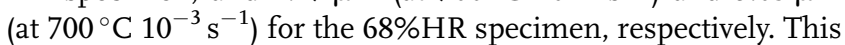
result means that dynamic grain growth is retarded for the heterogeneous starting microstructure of the $39 \% \mathrm{HR}$ specimen, which is attributable to the frequent activation of DRX occurred in the fine lamellar $\alpha$-grains. It is recognized that superplasticity requires a grain size $d$, which is smaller than the equilibrium subgrain size, $\lambda$, associated with the imposed stress, ${ }^{[21]}$ that is, grain boundaries. Thus, frequent occurrence of DRX contributes to an accommodation mechanism. According to the EBSD-localmisorientation results, the determined sizes of subgrain (formed in the elongated grain after deformation) in the deformed $39 \% \mathrm{HR}$ specimen are $0.74 \mu \mathrm{m}$ (tested at $10^{-2} \mathrm{~s}^{-1}$ ) and $1.0 \mu \mathrm{m}$ (tested at $10^{-3} \mathrm{~s}^{-1}$ ), respectively. So, in the fine equiaxed grained region with sizes less than the above subgrain size, the GBS is active deformation mode at and from initial stage of deformation. Enhancement of superplasticity requires frequent activation of GBS and accommodation mechanism simultaneously. Therefore, optimized microstructure for enhancing superplasticity is supposed to be obtained in the $39 \% \mathrm{HR}$ specimen having the heterogeneous microstructure composed of ultrafine equiaxed $\alpha$ grains (with a fraction of $65 \%$ ) and fine lamellar $\alpha$-grains (with a fraction of $35 \%$ ), that is, GBS and accommodation mechanism (caused by frequent occurrence of DRX) are optimally activated in the $39 \% \mathrm{HR}$ specimen. In fact, the highest elongation to fracture of $583 \%$ is obtained in the $39 \% \mathrm{HR}$ specimen (tested at $700^{\circ} \mathrm{C} 10^{-3} \mathrm{~s}^{-1}$ ). While, an excellent ductility is obtained in the $68 \% \mathrm{HR}$ specimen at the higher strain rate of $10^{-2} \mathrm{~s}^{-1}$, implying that the accommodation mechanism is not so activated at the higher strain rate condition of $10^{-2} \mathrm{~s}^{-1}$ for the $39 \% \mathrm{HR}$ specimen. From Figure 4a-d, it can be also observed that the density of GNDs is lower at the gage section than at the grip section, revealing that GBS is indeed active deformation mode rather than dislocation slip. Further, it has been reported that grain boundary sliding along a heterogeneous interface is faster compared to that along a homogeneous interface. ${ }^{[22,23]}$ So, in the heterogeneous starting microstructure, heterogeneous boundaries in which dislocations strongly accumulated is also assumed to enhance the GBS. Regarding the role of the $\beta$ phase on deformation, the $\beta$ phase acts like a soft and deformable mantle as in the Gifkins coremantle model. ${ }^{[24]}$ The $\beta$ phase volume fraction of $20 \%$ is estimated to be optimum for superplastic deformation. ${ }^{[25]}$ This is owing to the suppression of grain growth and easier grain boundary sliding at the $\alpha / \beta$-boundary. ${ }^{[26,27]}$ Further, Koike et al. suggested that the stress-induced phase transformation $(\alpha / \beta)$ also acted as an additional accommodation mechanism. ${ }^{[13]}$ From Figure 4 , 

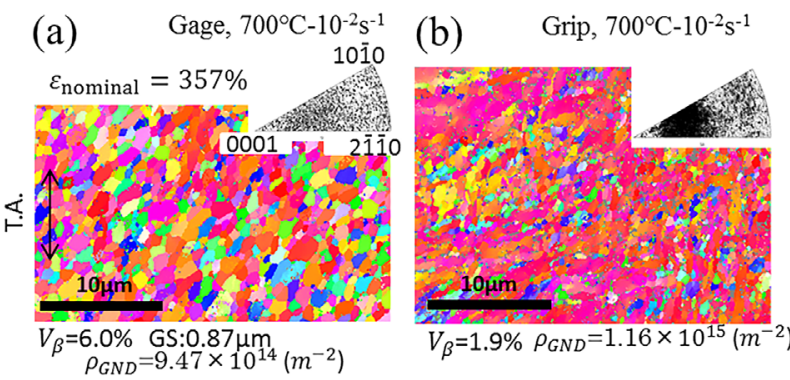

(e)
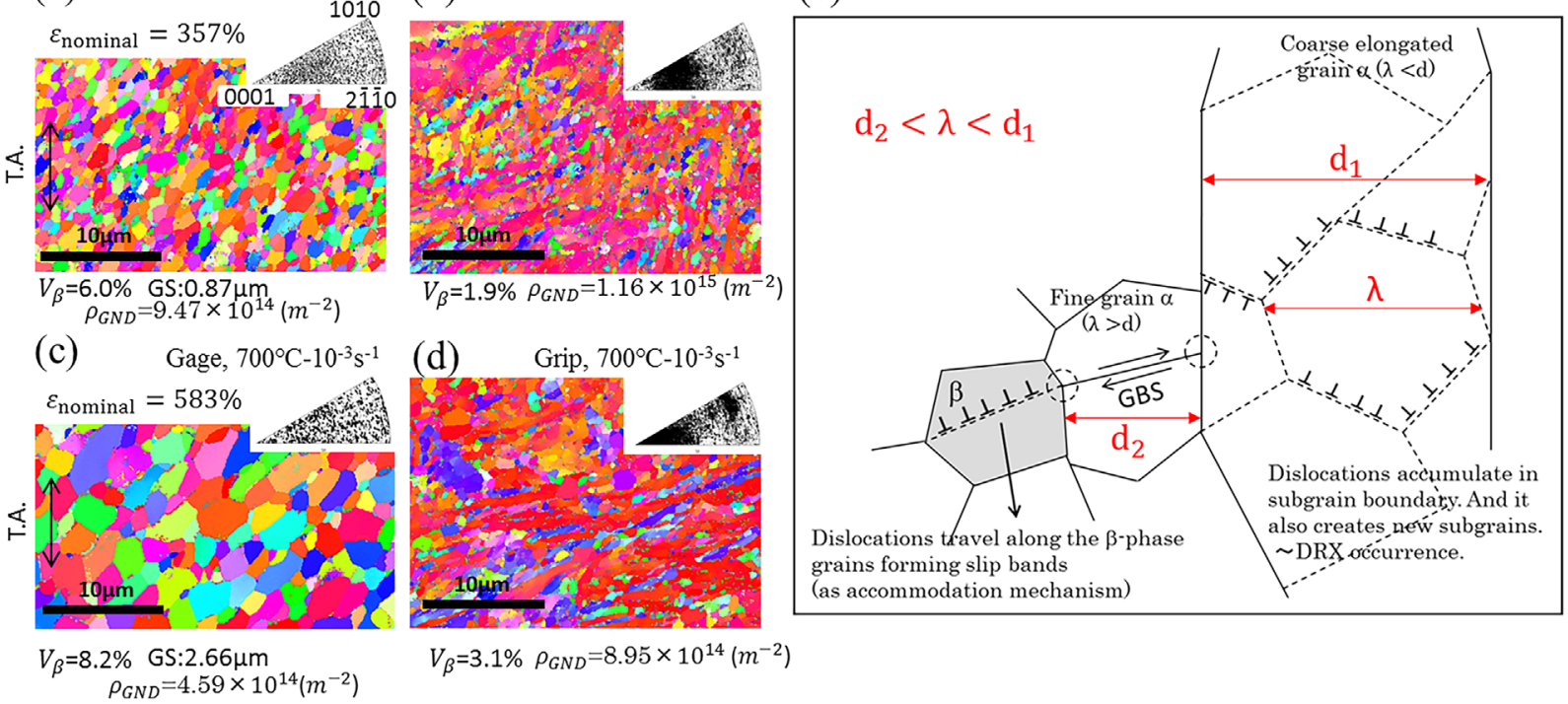

$V_{\beta}=3.1 \% \rho_{G N D}=8.95 \times 10^{14}\left(\mathrm{~m}^{-2}\right)$

Figure 4. a-d) EBSD-orientation images and inverse pole figures at the gage sections a) c) and the grip sections b) d) after tensile deformation of the $39 \% \mathrm{HR}$ specimen tested at a) b) $700^{\circ} \mathrm{C}^{-2} 0^{-2} \mathrm{~s}^{-1}$ and c) d) $700^{\circ} \mathrm{C} 10^{-3} \mathrm{~s}^{-1}$. Herein, a-d) exhibit the orientations at normal direction to the rolling plane. e) Schematic illustrations showing the operative deformation mode in regions of the equiaxed grain and the fine lamellar grain.

it can be noted a higher fraction of $\beta$ phase in the gage section than in the grip section, which is indicative of an occurrence of excessive $\beta$ precipitation in order to accommodate the stress concentration at boundaries. Thus, dynamic $\beta$ precipitation during deformation from metastable starting microstructure (as shown in Figure 1) should also act as an additional accommodation mechanism.

It is generally accepted that fine grained and equiaxed microstructure enables excellent superplastic behavior in $\mathrm{Ti}$ alloy. Furthermore, the role of the ultrafine-grained-equiaxedmicrostructure on deformation process associated with an occurrence of superplasticity has been mentioned in detail. ${ }^{[5,9,10]}$ To summarize this work, it can be emphasized that the GBS and accommodation mechanisms (caused by DRX and dynamic $\beta$ precipitation at boundaries) are optimally activated (under the lowtemperature-superplasticity at the specific-strain-rate-condition) by optimizing the starting microstructure, so as to have an ultrafinegrained heterogeneous microstructure composed of fine equiaxed $\alpha$-grains and fine lamellar $\alpha$-grains. Herein, frequent activation of accommodation mechanisms in the ultrafine-grained heterogeneous starting microstructure is of particular importance. In order to clarify it, further experiments are underway to identify the role of the microstructural heterogeneity and an optimized fraction (of approximately 35\%) of the fine-lamellar- $\alpha$-grain-region on enhancement of low-temperature-high -strain-rate (at $10^{-3} \mathrm{~s}^{-1}$ ) superplasticity with the detailed study on deformed microstructures according to TEM observations.

\section{Conclusions}

The Ti-64 alloy having an ultrafine grained heterogeneous microstructure composed of equiaxed grains and fine lamellar grains are produced by a conventional hot-rolling process (with changing the rolling reduction) by deforming of the $\alpha^{\prime}$ martensite microstructure. The lower flow stress and the higher strain rate sensitivity (at true plastic strain of 0.1 ) are obtained for the specimen with increasing a fraction of the equiaxed-grained-region. The $39 \%$ HR specimen having an optimum fraction of fine lamellar $\alpha$-grains exhibits an excellent superplastic property with the highest

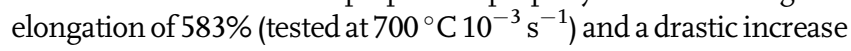
in strain rate sensitivity during deformation, which is attributable to the optimized activation of the GBS and an additional accommodation mechanisms (due to DRX and dynamic $\beta$ precipitation). Thus, this result points out the possibility that optimizing the starting microstructure so as to have an optimum heterogeneous-microstructure serves as an additional stress accommodation mechanism and leads to a large superplastic elongation.

\section{Acknowledgement}

This research was partially supported by a Grant-in-aid from Japan Society for the Promotion of Science (JSPS, number 16H04537).

\section{Conflict of Interest}

The authors declare no conflict of interest.

\section{Keywords}

accommodation mechanism, dynamic recrystallization, low-temperaturesuperplasticity, Ti-6Al-4V alloy, ultrafine-grained microstructure

[1] R. Boyer, G. Welsch, E. W. Collings, Materials Properties Handbook, Titanium Alloys, ASM International, Materials Park, OH 1994, p. 483. 
[2] C. Leyens, M. Peter, Titanium and Titanium Alloys: Fundamentals and Applications, Wiley-VCH Verlag GmbH \& Co. KGaA, Germany 2003, p. 276.

[3] R. S. Mishra, V. V. Stolyarov, C. Echer, R. Z. Valiev, A. K. Mukherjee, Mater. Sci. Eng. 2001, A298, 44.

[4] Y. G. Ko, W. G. Kim, C. S. Lee, D. H. Shin, Mater. Sci. Eng. 2005, A410-411, 156.

[5] A. V. Sergueeva, V. V. Stolyarov, R. Z. Valiev, A. K. Mukherjee, Scr. Mater. 2000, 43, 819

[6] H. Matsumoto, K. Yoshida, S. H. Lee, Y. Ono, A. Chiba, Mater. Lett. 2013, 98, 209.

[7] R. Z. Valiev, R. K. Islamgaliev, I. P. Semenova, Mater. Sci. Eng. 2007, A463, 2.

[8] S. Zherebtsov, E. Kudryavtsev, S. Kostjuchenko, S. Malysheva, G. Salishchev, Mater. Sci. Eng. 2012, A536, 190.

[9] E. Alabort, P. Kontis, D. Barba, K. Dragnevski, R. C. Reed, Acta Mater. 2016, 105, 449.

[10] S. V. Zherebtsov, E. A. Kudryavtsev, G. A. Salishchev, B. B. Straumal, S. L. Semiatin, Acta Mater. 2016, 121, 152.

[11] T. G. Nieh, J. Wadsworth, O. D. Sherby, Superplasticity in Metals and Ceramics, University Press, Cambridge 1997.

[12] A. K. Mukherjee, Mater. Sci. Eng. 2002, A322, 1.

[13] J. Koike, Y. Shimoyama, I. Ohnuma, R. Kainuma, K. Ishida, K. Maruyama, Acta Mater. 2000, 48, 2059.
[14] H. Matsumoto, V. Velay, A. Chiba, Mater. Des. 2015, 66, 611.

[15] H. Matsumoto, T. Nishihara, Y. Iwagaki, T. Shiraishi, Y. Ono, A. Chiba, Mater. Sci. Eng. 2016, A661, 68.

[16] M. Motyka, J. Sieniawski, Mater. Sci. Forum 2016, 838-839, 143.

[17] M. Calcagnotto, D. Ponge, E. Demir, D. Raabe, Mater. Sci. Eng. 2010, A527, 2738.

[18] H. Matsumoto, L. Bin, S. H. Lee, Y. Li, Y. Ono, A. Chiba, Metall. Mater. Trans. 2013, 44A, 3245

[19] Y. G. Ko, C. S. Lee, D. H. Shin, S. L. Semiatin, Metall. Mater. Trans. 2006, 37A, 381

[20] N. Cabanas, N. Akdut, J. Penning, B. C. DeCooman, Metall. Mater. Trans. 2006, 37A, 3305

[21] F. A. Mohamed, T. G. Langdon, Scr. Metall. 1976, 10, 759.

[22] A. Eberhardt, B. Baudelet, Philos Mag. 1980, 41A, 843.

[23] T. G. Nieh, J. Wadsworth, Acta Metall. Mater. 1991, 39, 3037.

[24] R. C. Gifkins, Superplastic Forming of Structural Alloys (Eds: N. E. Paton, C. H. Hamilton), TMS-AIME, Warrendale 1982, p. 3.

[25] T. Seshacharyulu, S. C. Medeiros, W. G. Frazier, Y. V. R. K. Prasad, Mater. Sci. Eng. 2000, A284, 184.

[26] J. S. Kim, Y. W. Chang, C. S. Lee, Metall. Mater. Trans. 1998, 29A, 217.

[27] S. M. L. Sastry, P. S. Pao, K. K. Sankaran, Titanium 80, Science Technology Vol.2 (Eds: H. Kimura, O. Izumi), AIME, New York 1980, p. 873. 